\title{
Use of Zeolite ZSM-5 for Loading and Release of 5-Fluorouracil
}

\author{
Ruba A. Al-Thawabeia and Hamdallah A. Hodali \\ Department of Chemistry, Faculty of Sciences, The University of Jordan, Amman 11942, Jordan \\ Correspondence should be addressed to Hamdallah A. Hodali; h-hodali@ju.edu.jo
}

Received 3 June 2015; Accepted 21 July 2015

Academic Editor: Jose L. Arias

Copyright (c) 2015 R. A. Al-Thawabeia and H. A. Hodali. This is an open access article distributed under the Creative Commons Attribution License, which permits unrestricted use, distribution, and reproduction in any medium, provided the original work is properly cited.

\begin{abstract}
Samples of zeolite ZSM-5 have been synthesized in both the sodium form (ZSM-5) and the acid activated form (H-ZSM-5). In addition, each of these two forms was prepared in the two molar $\mathrm{SiO}_{2} / \mathrm{Al}_{2} \mathrm{O}_{3}$ ratios of 169 and 15 . All samples of these ZSM-5 derivatives were characterized by X-ray diffraction (XRD), nitrogen adsorption-desorption isotherms, thermal gravimetric analysis (TGA), X-ray fluorescence (XRF), and scanning electron microscopy (SEM). The samples were successfully loaded with the anticancer drug 5-fluorouracil (5-FU) with loading capacities varying from 22\% (for the sodium form having the lower molar $\mathrm{SiO}_{2} / \mathrm{Al}_{2} \mathrm{O}_{3}$ ratio of $15, \mathrm{ZSM}-5$-(15)) to $43 \%$ (for the corresponding acid form, H-ZSM-5-(15)). Percent release of the drug-loaded ZSM-5 samples into simulated body fluid (SBF) was measured at $\mathrm{pH} 7.4$ and $37^{\circ} \mathrm{C}$. The results showed a slight variation in the $\%$ release within the range 84-93\%, while the first-order rate constant $(k)$ varied from $2.2 \mathrm{~h}^{-1}$ for ZSM-5-(15) to $3.9 \mathrm{~h}^{-1}$ for $\mathrm{H}-\mathrm{ZSM}$ 5-(15). It was interesting to note that at the higher molar $\mathrm{SiO}_{2} / \mathrm{Al}_{2} \mathrm{O}_{3}$ ratios of 169, both the sodium form, ZSM-5-(169), and the acid form, H-ZSM-5-(169), exhibit an intermediate efficiency in either \% loading (38\%) or first-order kinetic release constant $(k=$ $\left.2.9 \mathrm{~h}^{-1}\right)$.
\end{abstract}

\section{Introduction}

Chemotherapy is the most commonly used route for cancer treatment employing organic- and inorganic-based drugs. However, most of these drugs are known for their poor physicochemical properties such as low solubility, low stability, short circulating half-life, and cytotoxicity [1]. One of the problematic drugs that have been widely used in anticancer chemotherapy is 5 -fluorouracil (Figure 1).

5-Fluorouracil (5-FU) is a water-soluble pyrimidine analogue which is widely used in the treatment of various kinds of cancer, especially colon, head, neck, and ovary cancers [2]. 5 -FU can be used in oral, topical, and aerosolized formulations [3]. As a derivative of uracil, it rapidly enters the cell where it is converted into active metabolites that disrupt RNA synthesis and acts as inhibitor of thymidylate synthase, a nucleotide synthesis enzyme [4]. However, the oral use of 5FU exhibits a short plasma half-life $(30 \mathrm{~min})$ as a result of its rapid enzymatic metabolism [5], which demands continuous high doses thus leading to high toxicity, incomplete and nonuniform oral distribution, drug resistance by tumor cells, and nonselective action against normal cells $[6,7]$.
Different delivery systems have been used to ensure prolonged and sustained release of 5-FU. Examples include hydrogels [8], biodegradable polymers [9], layered inorganic nanocomposites [6], mesoporous organosilica [10], magnetic nanocarriers [7], the clay mineral montmorillonite [11], organic-modified montmorillonite [12], hybrid $\mathrm{TiO}_{2} / \mathrm{ZnO}$ nanotubes [13], porous silica calcium phosphate nanocomposites [14], mesoporous silica systems [15], and thiol-functionalized mesoporous silica nanoparticles [16]. Recently, zeolites have been used in biomedical applications due to their biocompatibility and low toxicity $[17,18]$. The small pore size of zeolites $(0.3-0.8 \mathrm{~nm})$ that matches the size of small drug molecules, in addition to the tunable properties that can be obtained by varying the molar $\mathrm{SiO}_{2} / \mathrm{Al}_{2} \mathrm{O}_{3}$ ratio, adds more advantages for utilizing zeolites in the medicinal field. Zeolites have been used as delivery systems for different types of drugs, including the adsorption of sulfonamide antibiotics onto zeolite Y [19], the use of $\mathrm{NaY}$ zeolite for encapsulation of the anticancer drug $\alpha$-cyano-4-hydroxycinnamic acid [20], the study of sustained release of the anticancer drug doxorubicin from zeolite magnetite nanocomposites [21], and the loading onto and release of aspirin from zeolite HY [22]. 


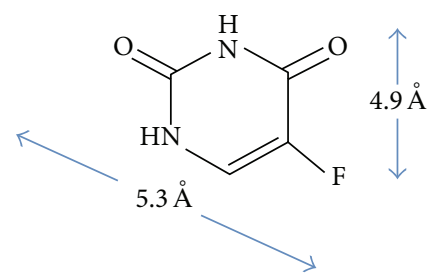

FIgURE 1: Chemical structure and molecular dimensions of 5fluorouracil (5-FU).

Recently, both zeolite HY [23] and zeolite NaX-FAU [24] have been explored as delivery systems for 5-FU.

In this study, zeolites ZSM-5 and H-ZSM-5, each prepared in two different molar $\mathrm{SiO}_{2} / \mathrm{Al}_{2} \mathrm{O}_{3}$ ratios (169 and 15), have been investigated as probable drug delivery systems for 5-FU. This choice of ZSM-5 zeolite derivatives for investigation as a possible drug carrier for 5-FU was dictated by their having a promising $3 \mathrm{D}$-channel structure with a suitable pore size, in addition to its reasonable good acid and thermal stability, in comparison with low silica zeolites.

\section{Materials and Methods}

2.1. Materials. Tetrapropylammonium bromide (+98\%, Acros Organics), aluminum sulfate $\mathrm{Al}_{2}\left(\mathrm{SO}_{4}\right)_{3} \cdot 16 \mathrm{H}_{2} \mathrm{O}$ (Interchem), sodium chloride $(\mathrm{BDH}), \mathrm{BaCl}_{2} \cdot 2 \mathrm{H}_{2} \mathrm{O}$ (Merck), $\mathrm{CaCl}_{2} \cdot 2 \mathrm{H}_{2} \mathrm{O}$ (Merck), $\mathrm{MgCl}_{2} \cdot 6 \mathrm{H}_{2} \mathrm{O}$ (SD Fine-Chem Limited), sodium metasilicate nonahydrate $\left(\mathrm{Na}_{2} \mathrm{SiO}_{3} \cdot 9 \mathrm{H}_{2} \mathrm{O}\right)$ (Aldrich), sulfuric acid (98\%, SD Fine-Chem Limited), ammonium nitrate (RPL), $\mathrm{NaHCO}_{3}$ (Merck), $\mathrm{KCl}$ (Riedel de Haën), $\mathrm{K}_{2} \mathrm{HPO}_{4} \cdot 3 \mathrm{H}_{2} \mathrm{O}$ (Merck), sodium hydroxide pellets (BDH), $\mathrm{Na}_{2} \mathrm{SO}_{4}$ (Merck), hydrochloric acid (35\%, SD Fine-Chem Limited), nitric acid (95\%, Merck), 5-fluorouracil (Acros Organics, 99\%), and tris(hydroxymethyl)aminomethane (Merck) were used as received. The simulated body fluid (SBF) was prepared following literature procedure [25] by dissolving the following salts into a $1 \mathrm{~L}$ solution with deionized water: $8.036 \mathrm{~g} \mathrm{NaCl}, 0.352 \mathrm{~g} \mathrm{NaHCO}_{3}, 0.225 \mathrm{~g}$ $\mathrm{KCl}, 0.230 \mathrm{~g} \mathrm{~K}_{2} \mathrm{HPO}_{4} \cdot 3 \mathrm{H}_{2} \mathrm{O}, 0.311 \mathrm{~g} \mathrm{MgCl}_{2} \cdot 6 \mathrm{H}_{2} \mathrm{O}, 40.0 \mathrm{~mL}$ $1 \mathrm{M} \mathrm{HCl}, 0.388 \mathrm{~g} \mathrm{CaCl}_{2} \cdot 2 \mathrm{H}_{2} \mathrm{O}, 0.072 \mathrm{~g} \mathrm{Na}_{2} \mathrm{SO}_{4}$, and $6.063 \mathrm{~g}$ tris(hydroxymethyl)aminomethane. The $\mathrm{pH}$ of solution was adjusted to 7.4 by $1 \mathrm{M} \mathrm{HCl}$ before being used.

2.2. Instrumentation (Physical Measurements). X-ray powder diffraction spectra were measured using a Philips $2 \mathrm{KW}$ model X-ray diffractometer $(\mathrm{Cu}-\mathrm{K} \alpha$ radiation source, $\lambda=$ $1.5418 \AA$ ) at a scan rate of $2^{\circ} \mathrm{C} / \mathrm{min}$. Specific surface areas were estimated through $\mathrm{BET}$ modeling using a nitrogen adsorption/desorption instrument (Nova 2200e). UV-Visible spectra were recorded using a Cary 100 Bio UV-Visible spectrophotometer (Varian). FT-IR spectra (4000 to $400 \mathrm{~cm}^{-1}$, $4 \mathrm{~cm}^{-1}$ spectral resolution, $\mathrm{KBr}$ pellets) were measured using a Thermo Nicolet NEXUS 670 FT-IR spectrometer. Thermal gravimetric analysis (TGA) was conducted using a Netzsch Sta 409 PC instrument (Netzsch-Ger) and a Mettler-Toledo DSC $823 \mathrm{E}$ instrument. The morphologies of the solid samples were monitored by scanning electron microscopy (SEM) using an FEI-FEG INSPEC F50 instrument. The chemical composition of samples was determined using an X-ray fluorescence spectrometer (SHIMADZU model XRF-1800).

2.3. Synthesis of ZSM-5. Samples of zeolite ZSM-5 with two different molar $\mathrm{SiO}_{2} / \mathrm{Al}_{2} \mathrm{O}_{3}$ ratios were prepared following a literature procedure [26], with some modifications. In a typical procedure, the zeolite was prepared by mixing three solutions 1, 2, and 3. Solution 1 was prepared by dissolving sodium silicate $\left(\mathrm{Na}_{2} \mathrm{SiO}_{3} \cdot 9 \mathrm{H}_{2} \mathrm{O}\right)$ (25.25 g) with deionized water $(20.0 \mathrm{~mL})$. Solution 2 was prepared by dissolving a specific amount of aluminum sulfate $\mathrm{Al}_{2}\left(\mathrm{SO}_{4}\right)_{3} \cdot 16 \mathrm{H}_{2} \mathrm{O}(0.40 \mathrm{~g}$ or $3.00 \mathrm{~g}$ depending on the required molar $\mathrm{SiO}_{2} / \mathrm{Al}_{2} \mathrm{O}_{3}$ ratio) and tetrapropylammonium bromide $(1.59 \mathrm{~g})$ in deionized water $(10.0 \mathrm{~mL})$. Solution 3 was prepared by dissolving sodium hydroxide $(0.36 \mathrm{~g})$ and sodium chloride $(5.25 \mathrm{~g})$ in deionized water $(15.0 \mathrm{~mL})$.

Solutions 2 and 3 were mixed, and then solution 1 was added dropwise. After vigorous stirring ( $30.0 \mathrm{~min})$, the $\mathrm{pH}$ was adjusted to the range $10.3-10.6$ by adding concentrated sulfuric acid (98\%). The hydrogel formed was transferred into an autoclave and heated for two days at $170^{\circ} \mathrm{C}$. The solid product was filtered and washed with deionized water until the filtrate is sulfate-free (tested by $\mathrm{BaCl}_{2}$ ). The zeolite was dried at $110^{\circ} \mathrm{C}$ for one hour and then calcined at $550^{\circ} \mathrm{C}$ for $5 \mathrm{~h}$ to allow for the decomposition of the template.

2.4. Acid Activation of Zeolite ZSM-5. The sodium zeolite ZSM-5 was acid activated into H-ZSM-5 using the following typical procedure: a sample of ZSM-5 (1.00 g) was added to a 2.0 M solution of ammonium nitrite $(50.0 \mathrm{~mL})$ and the mixture was placed in a thermostated water bath/shaker at $80^{\circ} \mathrm{C}$ for $24 \mathrm{~h}$, to obtain the ammonium exchanged zeolite, $\mathrm{NH}_{4}$ ZSM-5. The ammonium form of the zeolite was transformed to the acid form (H-ZSM-5) by calcination at $500^{\circ} \mathrm{C}$ for $4 \mathrm{~h}$ [27].

2.5. Loading of 5-FU into ZSM-5. 5-FU was loaded into samples of ZSM- 5 with two different molar $\mathrm{SiO}_{2} / \mathrm{Al}_{2} \mathrm{O}_{3}$ ratios via the following general procedure: 5 -FU $(\approx 0.400 \mathrm{~g})$ was dissolved in water $(25.0 \mathrm{~mL})$ and then added to a flask containing ZSM-5 ( 0.200 g). The mixture was stirred in the dark, at room temperature, for $24 \mathrm{~h}$. The drug-loaded carrier was filtered and dried under vacuum $(30 \mathrm{mmHg})$ for two hours at $60^{\circ} \mathrm{C}$.

The loading capacities of drug-loaded samples were determined by TGA measurements within the temperature range $25-1100^{\circ} \mathrm{C}$, under nitrogen. The drug loading capacity was also determined by UV-Visible absorption spectrophotometer, in which a predetermined amount of drug-loaded carrier (around $0.0100 \mathrm{~g}$ ) was stirred with water $(100.00 \mathrm{~mL})$ for 24 hours at room temperature, the solution was then filtered, and the concentration of 5-FU was determined by measuring the absorbance at $266 \mathrm{~nm}$. The total amount of drug contained in the sample was calculated with reference to a calibration curve.

2.6. 5-FU Release Profiles. The in vitro release of each 5FU-loaded carrier was measured using the dialysis method 
(dialysis bag diffusion technique). A 5-FU-loaded sample $(\sim 0.0500 \mathrm{~g})$ was introduced into a dialysis bag $(\mathrm{MWCO}=$ $3500 \mathrm{Da})$ containing SBF solution $(2.00 \mathrm{~mL} ; \mathrm{pH}=7.4)$. The sealed dialysis bag was immersed in a flask containing $198 \mathrm{~mL}$ SBF $(\mathrm{pH}=7.4)$. The flask was covered and placed in a thermostatic water bath/shaker maintained at $37^{\circ} \mathrm{C}$ and a constant shaking rate of $120 \mathrm{rpm}$.

At predetermined time intervals $(1 / 60,5 / 60,0.5,1.0,2.0$, 3.0, 4.0, 5.0, 6.0, 7.0, 8.0, 9.0, 10.0, 11.0, 12.0, and 13 hours), an aliquot $(1.000 \mathrm{~mL})$ was withdrawn from the flask and replaced by a fresh sample of SBF $\left(1.000 \mathrm{~mL}, 37.0^{\circ} \mathrm{C}\right)$ to maintain a constant volume. The release experiments were conducted in triplicate.

The concentration of 5 -FU released was determined by measuring the absorbance at $266 \mathrm{~nm}$ relative to a calibration curve of 5-FU in SBF. The calibration curve covered the concentration range of 0.50 to $20.00 \mathrm{ppm}$.

\section{Results and Discussion}

3.1. Synthesis of ZSM-5 and H-ZSM-5. ZSM-5 (sodium form) was prepared with two molar $\mathrm{SiO}_{2} / \mathrm{Al}_{2} \mathrm{O}_{3}$ ratios (169 and 15) by using a constant amount of sodium silicate and changing the aluminum content in the hydrogel (Table 1). Zeolite ZSM5 was then acid activated into H-ZSM-5 via a two-step procedure; the first step involves exchange of the sodium ion by ammonium ion to form $\mathrm{NH}_{4}-\mathrm{ZSM}-5$, which is then transformed into the acid form (H-ZSM-5) by calcination.

\subsection{Characterization of ZSM-5 and H-ZSM-5}

3.2.1. X-Ray Diffraction. The XRD spectra of ZSM-5 samples having the molar $\mathrm{SiO}_{2} / \mathrm{Al}_{2} \mathrm{O}_{3}$ ratios of 15 and 169 appear almost exactly the same. Similarly, the XRD spectra for the acid activated samples were in agreement with the typical pattern for zeolite ZSM-5, thus confirming that the zeolite keeps its structure and crystallinity upon acid activation as shown in the spectra of ZSM-5-(15) and H-ZSM-5-(15) depicted in Figure 2.

3.2.2. Nitrogen Adsorption-Desorption Isotherms. In an ideal case, microporous materials should exhibit type I isotherm according to IUPAC classification [27]. A representative nitrogen adsorption-desorption isotherm of ZSM-5 samples is shown in Figure 3. In the relative pressure $P / P_{0}$ range from 0.0 to 1.0 , the adsorption increased gradually with relative $P / P_{0}$ due to monolayer adsorption of $\mathrm{N}_{2}$ onto the microporous channels of ZSM-5. The desorption curve is very close to the adsorption curve in the whole range of $P / P_{0}$. It was reported that highly siliceous ZSM-5 exhibits two hysteresis loops: one at high relative pressure and the other at low relative pressure, which eventually disappears as the aluminum content increases [28, 29].

The specific surface areas of ZSM-5 derivatives were estimated from the adsorption branch using the BrunauerEmmett-Teller (BET) theory [30]. The results (Table 2) indicate a higher surface area for the acid activated sample than that of the corresponding sodium form. It also shows an

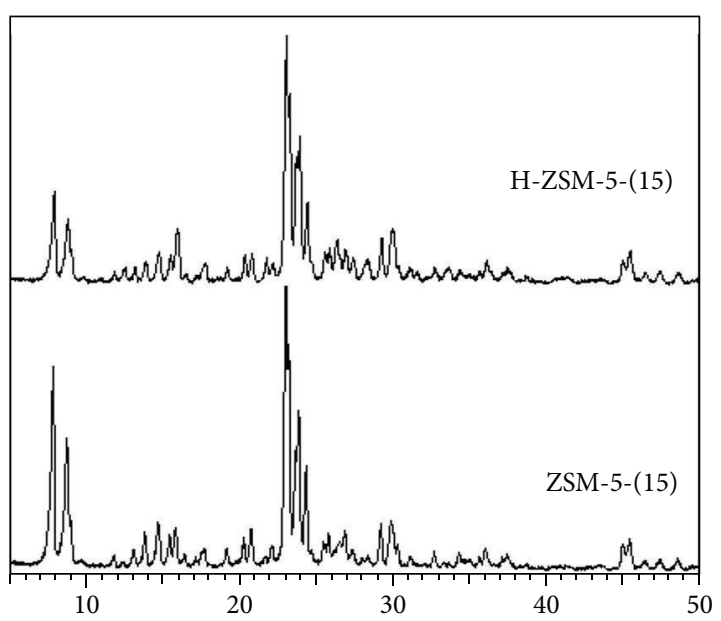

FIgURE 2: XRD spectra of ZSM-5 and H-ZSM-5 having a molar $\mathrm{SiO}_{2} / \mathrm{Al}_{2} \mathrm{O}_{3}$ ratio of 15 .

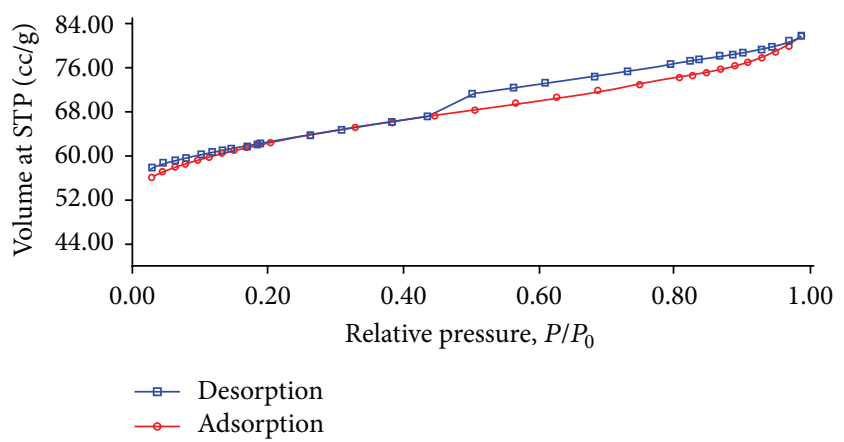

FIGURE 3: A typical nitrogen adsorption-desorption isotherm for ZSM-5-(15).

increase in the surface area with an increase in the molar $\mathrm{SiO}_{2} / \mathrm{Al}_{2} \mathrm{O}_{3}$ ratio, for both forms [31].

As to the effect of variations in acid activation and/or molar $\mathrm{SiO}_{2} / \mathrm{Al}_{2} \mathrm{O}_{3}$ ratio on the specific surface area of ZSM-5 zeolite, the following three observations are evident:

(i) For the acid activated form H-ZSM-5, increasing the molar $\mathrm{SiO}_{2} / \mathrm{Al}_{2} \mathrm{O}_{3}$ ratio from 15 to 169 raises the specific surface area by $\approx 50 \%$ (247 up to $369 \mathrm{~m}^{2} / \mathrm{g}$ ).

(ii) For the sodium form ZSM-5, increasing the molar $\mathrm{SiO}_{2} / \mathrm{Al}_{2} \mathrm{O}_{3}$ ratio from 15 to 169 raises the specific surface area by $\approx 70 \%$ (194 up to $326 \mathrm{~m}^{2} / \mathrm{g}$ ).

(iii) For the sodium form ZSM-5, a combination of acid activation and increase in the molar $\mathrm{SiO}_{2} / \mathrm{Al}_{2} \mathrm{O}_{3}$ ratio, from 15 to 169 , raises the specific surface area by $\approx 90 \%$ (194 up to $369 \mathrm{~m}^{2} / \mathrm{g}$ ). Therefore, a combination of increasing molar $\mathrm{SiO}_{2} / \mathrm{Al}_{2} \mathrm{O}_{3}$ ratio and acid activation of ZSM-5 yields the highest specific surface area.

3.2.3. Scanning Electron Microscopy (SEM) Micrographs of ZSM-5. Estimates of the sizes of ZSM-5 and H-ZSM-5 particles, and their morphologies, were obtained through SEM micrographs. All micrographs depict homogeneous distribution of particles, with no significant effect of molar 
TABLE 1: ZSM-5 sample preparation with molar $\mathrm{SiO}_{2} / \mathrm{Al}_{2} \mathrm{O}_{3}$ ratios of 169 and 15 .

\begin{tabular}{lccc}
\hline Sample & $\mathrm{NaSiO}_{3} \cdot 9 \mathrm{H}_{2} \mathrm{O}$ mass $(\mathrm{g})$ & $\mathrm{Al}_{2}\left(\mathrm{SO}_{4}\right)_{3} \cdot 16 \mathrm{H}_{2} \mathrm{O}$ mass $(\mathrm{g})$ & $\mathrm{SiO}_{2} / \mathrm{Al}_{2} \mathrm{O}_{3}{ }^{* *}$ \\
\hline ZSM-5-(169) & 25.25 & 0.400 & 169 \\
ZSM-5-(15) & 25.25 & 3.000 & 15 \\
\hline
\end{tabular}

* The number in brackets refers to the molar $\mathrm{SiO}_{2} / \mathrm{Al}_{2} \mathrm{O}_{3}$ ratio.

${ }^{* *}$ Molar ratios, determined by XRF.

TABLE 2: Specific surface area $(A)$ for the synthesized zeolite ZSM-5.

\begin{tabular}{lcc}
\hline Zeolite sample & $\mathrm{SiO}_{2} / \mathrm{Al}_{2} \mathrm{O}_{3}$ (molar ratio) & $A\left(\mathrm{~m}^{2} / \mathrm{g}\right)$ \\
\hline ZSM-5-(15) & 15 & 194 \\
ZSM-5-(169) & 169 & 326 \\
H-ZSM-5-(169) & 169 & 369 \\
H-ZSM-5-(15) & 15 & 247 \\
\hline
\end{tabular}

$\mathrm{SiO}_{2} / \mathrm{Al}_{2} \mathrm{O}_{3}$ ratio or acid activation on their size or shape. Some of the particles have elongated cubic shapes while others have hexagonal prismatic units with particle size distributions in the range of $0.4-0.8 \mu \mathrm{m}$. Examples of these micrographs are depicted for ZSM-5-(15) and H-ZSM-5-(15) in Figure 4.

\subsection{Loading and Release of 5-FU}

3.3.1. 5-FU Loading into Zeolite ZSM-5. With the dimensions shown in Figure 1,5-FU is expected to enter the micropores of ZSM-5 readily. 5-FU was loaded into samples of zeolites ZSM-5 and H-ZSM-5 with the two different molar $\mathrm{SiO}_{2} / \mathrm{Al}_{2} \mathrm{O}_{3}$ ratios 169 and 15 by the impregnation method. The optimum conditions to obtain the highest \% loading were attained using an aqueous $25.00 \mathrm{~mL}$ of $16.00 \mathrm{mg} / \mathrm{mL}$ solution of 5 -FU and $0.20 \mathrm{~g}$ of the zeolite carrier $(2: 1$ mass ratio of drug to carrier) and a stirring period of 24 hours. Loading of the drug into the ZSM-5 was confirmed by FTIR-spectrometry and XRD spectra. Inspection of the FTIR spectra of ZSM-5, 5-FU, and loaded ZSM-5, in the region $2000-1500 \mathrm{~cm}^{-1}$, confirms the presence of the drug in the loaded zeolite. The strong band centered at about $1770 \mathrm{~cm}^{-1}$ in the spectrum of free 5-FU (which is absent from the spectrum of unloaded ZSM-5) appears as a very weak band in the spectra of loaded ZSM-5 and loaded H-ZSM-5. Such drastic decrease in intensity is characteristic of compounds enclosed by porous materials [23]. Drug loading was also confirmed by the appearance of the 5-FU characteristic peak at $2 \theta=29^{\circ}$ in the XRD-spectrum of the drug-loaded ZSM-5 (Figure 5). This is an indication of 5-FU crystallization in the carrier pores.

The zeolite loading capacity for 5-FU was determined from the TGA thermograms of pure ZSM-5 and ZSM-5 loaded with 5-FU. Figure 6(a) shows decomposition of 5-FU within the range $280-350^{\circ} \mathrm{C}$ (m.p. of $5-\mathrm{FU}=282-286^{\circ} \mathrm{C}$ ). However, one of the drug-loaded samples, 5-FU-ZSM-5-(15), lost about $40 \%$ of its mass below $400^{\circ} \mathrm{C}$ but eventually ended with $50 \%$ residual mass at $1100^{\circ} \mathrm{C}$, thus indicating the thermal stability of the silicate carrier.

The zeolite loading capacity was also estimated by UVVisible spectrophotometry, according to the following equation:

$$
\% \text { Drug loading }=\frac{\text { Mass of drug loaded into carrier (estimated by UV absorption })}{\text { Mass of loaded carrier }} \times 100
$$

Table 3 lists \% loading of 5-FU into the sodium form of zeolite (ZSM-5) and the corresponding acid activated form (H-ZSM-5) for each of the two molar $\mathrm{SiO}_{2} / \mathrm{Al}_{2} \mathrm{O}_{3}$ ratios, 169 and 15. Inspection of the table indicates that the estimates of $\%$ loading, obtained for each of the four zeolite derivatives from TGA thermograms and UV absorption, are equivalent within experimental error.

In view of data presented in Table 3, a lower molar $\mathrm{SiO}_{2} / \mathrm{Al}_{2} \mathrm{O}_{3}$ ratio plus acid activation of the sodium form of ZSM-5 yields the highest loading capacity for 5-FU. For example, at the lower molar $\mathrm{SiO}_{2} / \mathrm{Al}_{2} \mathrm{O}_{3}$ ratio of 15 , acid activation of ZSM-5 doubles the \% loading of 5-FU ( $22 \%$ up to $43 \%)$.

3.3.2. 5-FU Release from Zeolite ZSM-5. The in vitro cumulative release of 5 -FU loaded into three different samples of zeolite ZSM-5 was studied. The effects of variation in the molar $\mathrm{SiO}_{2} / \mathrm{Al}_{2} \mathrm{O}_{3}$ ratio on the release profiles of 5 - $\mathrm{FU}$ that was loaded into ZSM-5 having a molar $\mathrm{SiO}_{2} / \mathrm{Al}_{2} \mathrm{O}_{3}$ ratio of 15 and also into ZSM-5 having a molar ratio of 169 were measured. In addition, the effect of acid activation of zeolite on the release profile from ZSM-5 and H-ZSM-5 having the same molar $\mathrm{SiO}_{2} / \mathrm{Al}_{2} \mathrm{O}_{3}$ ratio (15) was also measured. The $\%$ release was evaluated utilizing the dialysis bag diffusion technique, in which dialysis bags with MWCO of $3500 \mathrm{Da}$ were used. The dialysis bags retain the carrier particles within the bag but allow the released free drug molecules to diffuse into the simulated body fluid (SBF) medium at $\mathrm{pH} 7.4$ and $37^{\circ} \mathrm{C}$.

At predetermined time intervals (as specified in the experimental section), aliquots were withdrawn from the release medium and were readily replaced by fresh samples of SBF at the same conditions, in order to maintain a constant SBF volume. The release experiments were conducted in 

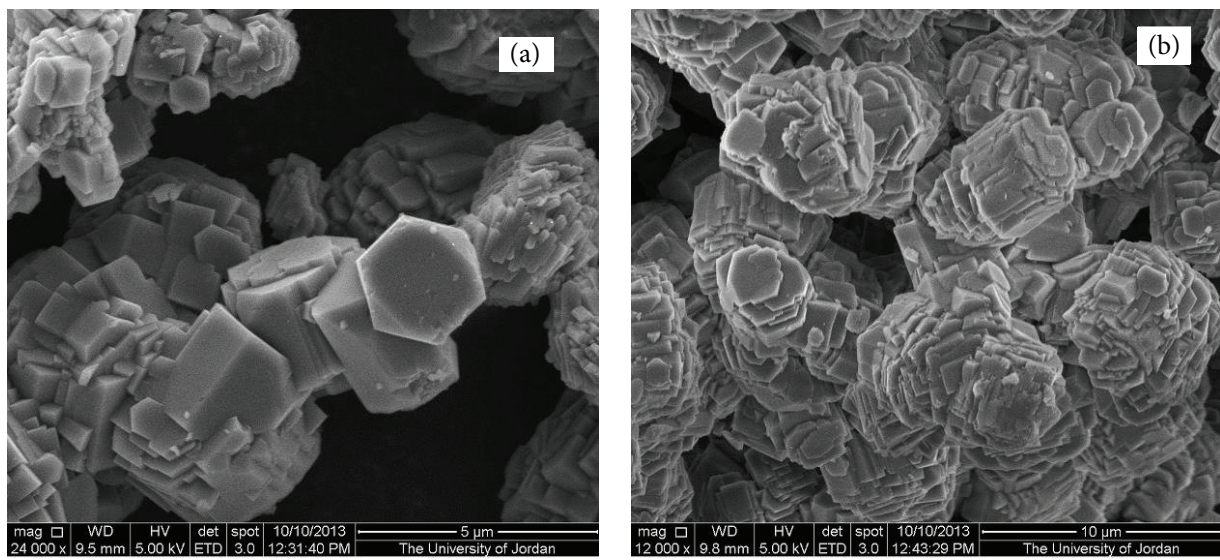

FIgURE 4: SEM micrographs of (a) ZSM-5-(15) and (b) H-ZSM-5-(169).
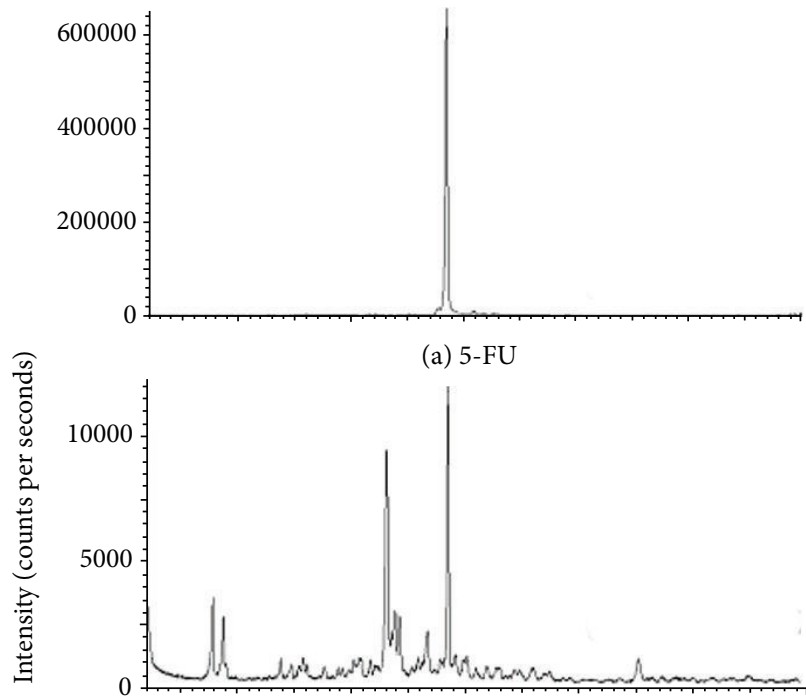

(b) 5-FU-ZSM-5

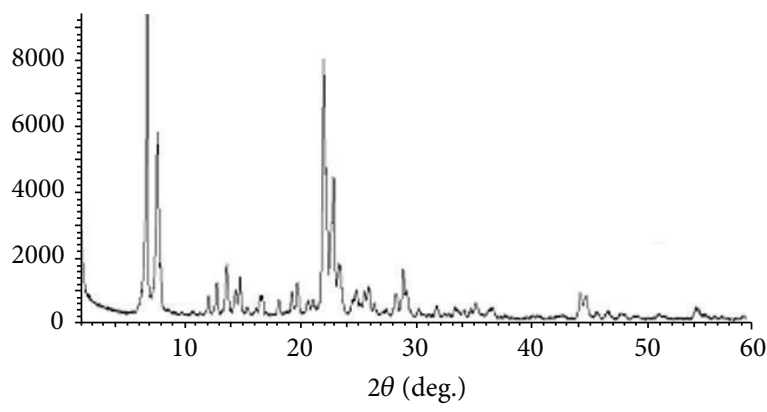

(c) ZSM-5

FIGURE 5: XRD of (a) 5-FU, (b) ZSM-5-(15) loaded with 5-FU, and (c) unloaded ZSM-5-(15).

triplicate, and corresponding data averages of the three experiments were used for nonlinear regression analysis.

The withdrawn samples were analyzed for 5-FU concentration by measuring the absorbance at $\lambda_{\max }=266 \mathrm{~nm}$, following appropriate dilution and using a blank sample for base

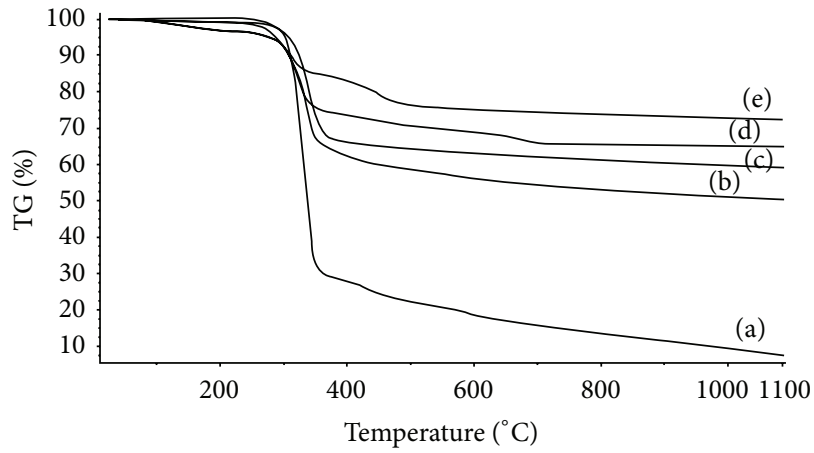

FIGURE 6: TGA thermograms of (a) 5-FU, which shows a residual mass of $6.95 \%$, (b) 5-FU-ZSM-5-(15), with a residual mass of $50.02 \%$, (c) 5-FU-ZSM-5-(169), with a residual mass of 58.69\%, (d) 5-Fu-HZSM-5-(169), with a residual mass of 64.72\%, and (e) 5-Fu-H-ZSM5-(15), exhibiting a residual mass of $71.96 \%$.

line correction. The concentration of 5-FU $(C)$ was estimated with reference to a calibration curve of 5-FU, in $\mathrm{SBF}$ at the same conditions, according to

$$
C_{5-\mathrm{FU}}(\mathrm{ppm})=19.5380304 \times A_{266 \mathrm{~nm}}-0.0519868 .
$$

The measured concentration of 5-FU (in ppm) released into the buffer solution was used to estimate the cumulative drug release, $Q_{t}$, at time $t$. The cumulative release represents the total amount of drug released (in $\mathrm{mg}$ ) from the ZSM-5 carrier into the release medium, which was kept at a constant volume of $200 \mathrm{~mL}$. For each sampling time $t$, the amount of drug in all previously withdrawn samples is added to the amount of the drug in the release medium measured at time $t$, thus giving rise to the cumulative drug release, $Q_{t}$.

The first-order kinetic model was used to simulate the kinetics of the drug release process. Nonlinear regression analysis was used to fit the experimental cumulative drug release $\left(Q_{t}\right)$ against time $t$, to the first-order drug release model given by the following equation [32]:

$$
\frac{Q_{t}}{Q_{m}}=1-e^{-k t}
$$


TABLE 3: The measured \% loading of 5-FU into the four zeolite samples.

\begin{tabular}{lcc}
\hline Sample & \% loading (TGA data) & \% loading (UV data) \\
\hline ZSM-5-(169) & 38 & 38.0 \\
H-ZSM-5-(169) & 40 & 39.1 \\
ZSM-5-(15) & 21 & 22.0 \\
H-ZSM-5-(15) & 45 & 43.0 \\
\hline
\end{tabular}

where $Q_{t}$ is the cumulative drug release (in $\mathrm{mg}$ ), $Q_{m}$ is the maximum amount of drug (in $\mathrm{mg}$ ) that is released into the medium, $k$ is the release rate constant in $\mathrm{h}^{-1}$, and $t$ is the sampling time in hours.

Both $Q_{m}$ and $k$ were used as floating parameters in nonlinear regression of $Q_{t}$ against $Q_{m}\left(1-e^{-k t}\right)$, and the best parameter estimates, thus obtained, were used to obtain a corresponding estimate of the best data fit. The \% release was calculated by the normalization of the cumulative drug release of drug estimated for each time interval $\left(Q_{t}\right)$ into the total quantity of drug in the loaded ZSM-5 zeolite sample. Plots of \% release against time profiles for the three systems are depicted in Figure 7, where solid lines represent the best data fits.

The kinetic parameters for the release of 5-FU from the three carriers ZSM-5-(15), H-ZSM-5-(15), and ZSM-5-(169) are listed in Table 4. Analysis of those data indicates that upon acid activation the first-order release rate constant $(k)$ increases from $2.2 \mathrm{~h}^{-1}$ for ZSM-5-(15) to $3.9 \mathrm{~h}^{-1}$ for H-ZSM5-(15). The effect of molar $\mathrm{SiO}_{2} / \mathrm{Al}_{2} \mathrm{O}_{3}$ ratio can be seen by comparing the $k$ values for ZSM-5-(15) and ZSM-5-(169), which are $2.2 \mathrm{~h}^{-1}$ and $2.9 \mathrm{~h}^{-1}$, respectively. This might be attributed to the corresponding decrease of the aluminum content, which is responsible for the stronger attractive interaction forces between 5-FU and the zeolite ZSM-5 pore surface, thus impeding drug release. These results are in agreement with those reported for the release of 5-FU from zeolite HY [23].

The Higuchi square root time model [33], which is based on Fickian diffusion, was also applied to the initial first burst of drug release. This model assumes that the drug \% release varies with the square root of time $\left(t^{1 / 2}\right)$, which typically occurs relatively fast compared with subsequent release, and is given by the relation

$$
\frac{Q_{t}}{Q_{m}}=k_{H} t^{1 / 2}+c,
$$

where $Q_{t}$ is the mass of drug released at time $t, Q_{m}$ is the maximum mass released, $k_{H}\left(\mathrm{~h}^{-1 / 2}\right)$ is the Higuchi constant, and $c$ is a constant characteristic of the drug and host being formulated. Plots of \% release of 5-FU, from zeolite ZSM-5, against $t^{1 / 2}$ are depicted in Figure 8.

In addition, estimates of the individual contributions of drug diffusion $(A)$, and drug erosion (B), to 5 -FU first burst were obtained through nonlinear regression analysis of data using Kopcha's model [34] according to

$$
\frac{Q_{t}}{Q_{m}}=A t^{1 / 2}+B t .
$$

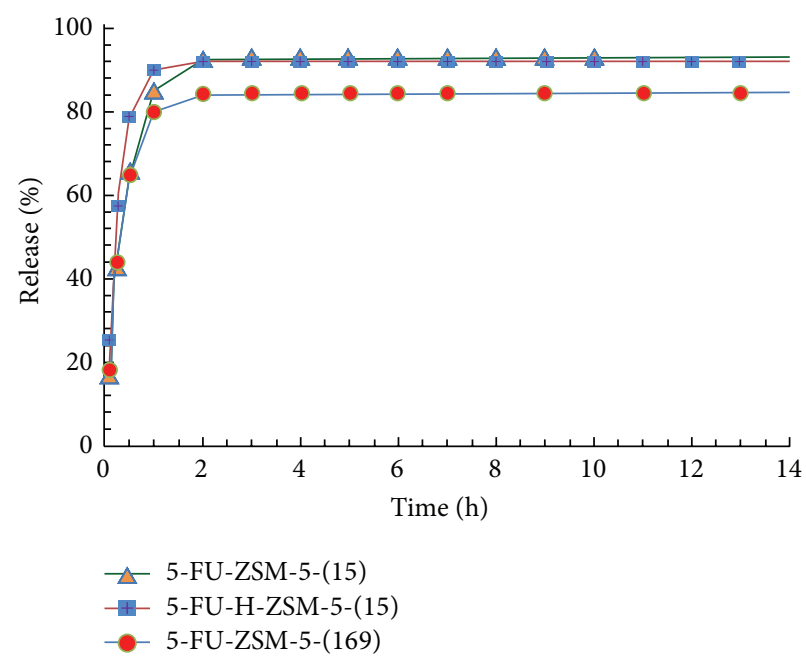

Figure 7: Percent release profiles of 5-FU from 5-FU-ZSM-5-(15) (triangles), 5-FU-H-ZSM-5-(15) (squares), and 5-FU-ZSM-5-(169) (circles). Solid lines passing through experimental data represent nonlinear regression into first-order release kinetics.

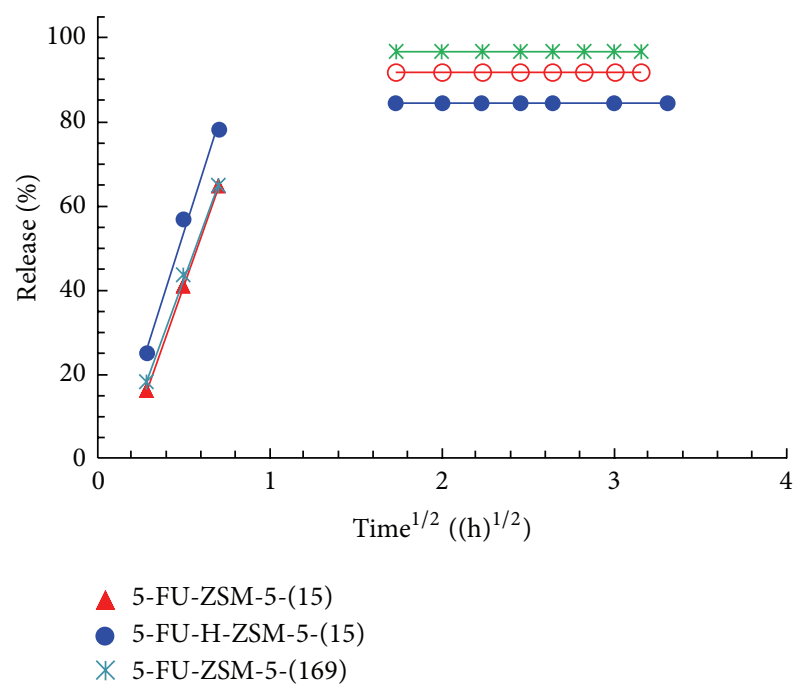

FIGURE 8: A plot of the $\%$ release, against $t^{1 / 2}$, of 5-FU from different samples of zeolite ZSM-5, all loaded with 5-FU, into SBF solution at $\mathrm{pH} 7.4$ and $37^{\circ} \mathrm{C}$.

The $A / B$ ratios thus obtained (Table 4 ) indicate that diffusion is the principal mechanism for release of 5-FU from zeolite ZSM-5 with different molar $\mathrm{SiO}_{2} / \mathrm{Al}_{2} \mathrm{O}_{3}$ ratios, both in the sodium and acid activated forms.

Table 5 lists the \% loading and \% release results of 5FU obtained in this work, in addition to related data on micro- and mesoporous silicates that have been published in the literature. Inspection of the data reveals the following observations:

(i) Successful use of zeolite ZSM-5 as a carrier for 5-FU with a relatively high loading capacity $(\geq 40 \%)$ can be partially attributed to the close matching between 
TABLE 4: Kinetic parameters of 5-FU release from sodium zeolite (ZSM-5) and the corresponding acid activated form (H-ZSM-5). Modeling of \% release $\left(Q_{t} / Q_{m}\right)$ was carried out utilizing each of the following models: the first-order release model $\left[Q_{t} / Q_{m}=1-e^{-k t}\right]$, Higuchi's first burst model $\left[Q_{t} / Q_{m}=k_{H} t^{1 / 2}+c\right]$, and Kopcha's model $\left[Q_{t} / Q_{m}=A t^{1 / 2}+B t\right]$.

\begin{tabular}{|c|c|c|c|c|c|c|c|c|}
\hline \multirow{3}{*}{ Zeolite } & \multirow{2}{*}{\multicolumn{3}{|c|}{ 5-FU loading data }} & \multicolumn{5}{|c|}{ 5-FU kinetic release models' data } \\
\hline & & & & & $/ Q_{m}=1-e$ & & $Q_{t} / Q_{m}=k_{H} t^{1 / 2}+c$ & $Q_{t} / Q_{m}=A t^{1 / 2}+B t$ \\
\hline & $W_{S}^{\mathrm{a}}(\mathrm{mg})$ & \% loading & $W_{D}^{\mathrm{b}}(\mathrm{mg})$ & $Q_{m}{ }^{c}(\mathrm{mg})$ & $\%$ release $^{\mathrm{d}}$ & $k^{\mathrm{e}}\left(\mathrm{h}^{-1}\right)$ & $k_{H}{ }^{\mathrm{f}}\left(\mathrm{h}^{-1 / 2}\right)$ & $A / B^{g}$ \\
\hline ZSM-5-(15) & 49.2 & 22 & 10.8 & 10.47 & 97 & 2.2 & 1.2 & 11.0 \\
\hline H-ZSM-5-(15) & 50.2 & 43 & 21.6 & 19.8 & 92 & 3.9 & 1.4 & 22.5 \\
\hline ZSM-5-(169) & 50.6 & 38 & 19.2 & 16.2 & 85 & 2.9 & 1.1 & 2.4 \\
\hline
\end{tabular}

${ }^{\mathrm{a}} W_{S}=$ average mass of the drug-loaded sample.

${ }^{\mathrm{b}} W_{D}=$ average mass of the drug in the loaded sample (obtained from $\%$ loading).

${ }^{\mathrm{c}} Q_{m}=$ maximum mass of drug released into the SBF buffer solution.

$\mathrm{d}_{\%}$ release $=100 \times Q_{t} / W_{D}$.

${ }^{\mathrm{e}} k=$ first-order rate constant.

${ }^{\mathrm{f}} k_{H}=$ Higuchi first burst constant.

${ }^{\mathrm{g}} A / B=$ ratio of diffusion-to-erosion contributions to drug release.

TABLE 5: A comparison of \% loading, \% release, and kinetic model parameter data of 5-FU obtained in this work, as well as related data on siliceous carriers published literature, for comparison.

\begin{tabular}{|c|c|c|c|c|c|}
\hline \multirow{3}{*}{ Siliceous material } & \multicolumn{4}{|c|}{ 5-FU kinetic release models' data } & \multirow{3}{*}{ Reference } \\
\hline & \multicolumn{3}{|c|}{$Q_{t} / Q_{m}=1-e^{-k t}$} & $Q_{t} / Q_{m}=k_{H} t^{1 / 2}+c$ & \\
\hline & \% loading & $\%$ release & $k\left(\mathrm{~h}^{-1}\right)$ & $k_{H}\left(\mathrm{~h}^{-1 / 2}\right)$ & \\
\hline ZSM-5-(15) & 22 & $97 \%$ after $3 \mathrm{hrs}$ & 2.2 & 1.2 & \multirow{3}{*}{ This work } \\
\hline H-ZSM-5-(15) & 43 & $92 \%$ after $3 \mathrm{hrs}$ & 3.9 & 1.4 & \\
\hline ZSM-5-(169) & 38 & $85 \%$ after 3 hrs & 2.9 & 1.1 & \\
\hline Zeolite NaX-FAU & 16 & $83 \%$ after $3 \min (0.1 \mathrm{M} \mathrm{HCl})$ & - & - & {$[24]$} \\
\hline Zeolite HY-60 & 9 & $63 \%$ after 5 hrs & 90 & - & {$[23]$} \\
\hline MCM-41 & 86 & $45 \%$ after $1 \mathrm{hr}, 95 \%$ after $26 \mathrm{hrs}$ & 0.24 & 3.3 & \multirow{2}{*}[16]{} \\
\hline Thiol-functionalized MCM-41 & 99 & $20 \%$ after 2 hrs, $95 \%$ after 18 hrs & 0.1 & 206 & \\
\hline
\end{tabular}

the size of ZSM-5 micropores and that of the 5-FU molecule.

(ii) Enhancements on the loading capacity and the firstorder rate constant $(k)$ were observed upon acid activation of ZSM-5 and also upon increasing the molar $\mathrm{SiO}_{2} / \mathrm{Al}_{2} \mathrm{O}_{3}$ ratio from 15 to 169 .

(iii) A relatively high \% release of 5-FU was achieved with the highest \% release exhibited by ZSM-5 having a molar $\mathrm{SiO}_{2} / \mathrm{Al}_{2} \mathrm{O}_{3}$ ratio of $169(\geq 85 \%)$.

(iv) The first-order rate constant $(k)$ increases with increasing the molar $\mathrm{SiO}_{2} / \mathrm{Al}_{2} \mathrm{O}_{3}$ ratio from $2.2 \mathrm{~h}^{-1}$ for Na-ZSM-5-(15) to $2.9 \mathrm{~h}^{-1}$ for Na-ZSM-5-(169) and increases upon acid activation (from $2.2 \mathrm{~h}^{-1}$ for $\mathrm{Na}$ ZSM-5-(15) to $3.9 \mathrm{~h}^{-1}$ for H-ZSM-5-(15)).

(v) Diffusion is the principal process governing $5-\mathrm{FU}$ release from zeolite ZSM-5.

\section{Conclusion}

In this research work, zeolite ZSM-5 was synthesized with two different molar $\mathrm{SiO}_{2} / \mathrm{Al}_{2} \mathrm{O}_{3}$ ratios, which were both acid activated. The acid activated $\mathrm{ZSM}-5$ with a molar $\mathrm{SiO}_{2} / \mathrm{Al}_{2} \mathrm{O}_{3}$ ratio of 169 shows the highest \% loading and \% release. As shown in Table 5, ZSM-5 exhibits about fourfold loading capacity and about twofold \% release of 5-FU as compared with zeolite Y. With its relative good thermal and acid stability (compared with low silica zeolites) in addition to its high \% loading $(\sim 40 \%)$ and $\%$ release $(\sim 85 \%)$, ZSM-5 may serve as a potential carrier for 5-FU.

\section{Conflict of Interests}

The authors declare that there is no conflict of interests regarding the publication of this paper.

\section{Acknowledgments}

The authors acknowledge the fruitful discussions of kinetic data with Professor M. Zughul. The authors gratefully acknowledge the financial support provided by the Deanship of Academic Research, The University of Jordan, Amman, Jordan, and Scientific Research Support Fund (Grant no. Bas/2/02/2012), Amman, Jordan.

\section{References}

[1] H. Zhu, J. Cao, S. Cui, Z. Qian, and Y. Gu, "Enhanced tumor targeting and antitumor efficacy via hydroxycamptothecinencapsulated folate-modified $\mathrm{N}$-succinyl- $\mathrm{N}^{\prime}$-octyl chitosan 
micelles," Journal of Pharmaceutical Sciences, vol. 102, no. 4, pp. 1318-1332, 2013.

[2] S. Yan, J. Zhu, Z. Wang, J. Yin, Y. Zheng, and X. Chen, "Layerby-layer assembly of poly(L-glutamic acid)/chitosan microcapsules for high loading and sustained release of 5-fluorouracil," European Journal of Pharmaceutics and Biopharmaceutics, vol. 78, no. 3, pp. 336-345, 2011.

[3] J. L. Arias, "Novel strategies to improve the anticancer action of 5-fluorouracil by using drug delivery systems," Molecules, vol. 13, no. 10, pp. 2340-2369, 2008.

[4] D. B. Longley, D. P. Harkin, and P. G. Johnston, "5-Fluorouracil: mechanisms of action and clinical strategies," Nature Reviews Cancer, vol. 3, no. 5, pp. 330-338, 2003.

[5] R. C. Mundargi, V. Rangaswamy, and T. M. Aminabhavi, "A novel method to prepare 5-fluorouracil, an anti-cancer drug, loaded microspheres from poly(N-vinyl caprolactam-co-acrylamide) and controlled release studies," Designed Monomers and Polymers, vol. 13, no. 4, pp. 325-336, 2010.

[6] B. D. Kevadiya, T. A. Patel, D. D. Jhala et al., "Layered inorganic nanocomposites: a promising carrier for 5 -fluorouracil (5-FU)," European Journal of Pharmaceutics and Biopharmaceutics, vol. 81, no. 1, pp. 91-101, 2012.

[7] J. L. Arias, M. López-Viota, Á. V. Delgado, and M. A. Ruiz, "Iron/ethylcellulose (core/shell) nanoplatform loaded with 5fluorouracil for cancer targeting," Colloids and Surfaces B: Biointerfaces, vol. 77, no. 1, pp. 111-116, 2010.

[8] N. P. Bayramgil, "Synthesis, characterization and drug release behavior of poly(1-vinyl 1,2,4-triazole) hydrogels prepared by gamma irradiation," Colloids and Surfaces B: Biointerfaces, vol. 97, pp. 182-189, 2012.

[9] X. Cai, Q. Zhao, Y. Luan, Y. Jiang, J. Shi, and W. Shao, "Polymer fibrous materials composed of sodium carboxymethylcellulose and poly(vinyl alcohol) for a hydrophilic anticancer drug release," Journal of Dispersion Science and Technology, vol. 33, no. 6, pp. 835-839, 2012.

[10] M. S. Moorthy, S.-S. Park, D. Fuping, S.-H. Hong, M. Selvaraj, and C.-S. Ha, "Step-up synthesis of amidoxime-functionalised periodic mesoporous organosilicas with an amphoteric ligand in the framework for drug delivery," Journal of Materials Chemistry, vol. 22, no. 18, pp. 9100-9108, 2012.

[11] F. H. Lin, Y. H. Lee, C. H. Jian, J.-M. Wong, M.-J. Shieh, and C.-Y. Wang, "A study of purified montmorillonite intercalated with 5-fluorouracil as drug carrier," Biomaterials, vol. 23, no. 9, pp. 1981-1987, 2002.

[12] S. Gârea, A. Mihai, A. Ghebaur, C. Nistor, and A. Sârbu, "Porous clay heterostructures: a new inorganic host for 5-fluorouracil encapsulation," International Journal of Pharmaceutics, vol. 491, no. 1-2, pp. 299-309, 2015.

[13] H. A. M. Faria and A. A. A. de Queiroz, "A novel drug delivery of 5-fluorouracil device based on $\mathrm{TiO}_{2} / \mathrm{ZnS}$ nanotubes," Materials Science and Engineering C, vol. 56, pp. 260-268, 2015.

[14] A. El-Ghannam, K. Ricci, A. Malkawi et al., "A ceramic-based anticancer drug delivery system to treat breast cancer," Journal of Materials Science: Materials in Medicine, vol. 21, no. 9, pp. 2701-2710, 2010.

[15] I. S. Carino, F. Testaa, F. Puocib, L. Pasquaa, and R. Aielloa, "Polymer coated silica-based mesoporous materials for controlled drug release," in Proceedings of the 4th International FEZA Conference, PIII-A66, Paris, France, September 2008.

[16] B. Murugan, L. N. Ramana, S. Gandhi, S. Sethuraman, and U. M. Krishnan, "Engineered chemoswitchable mesoporous silica for tumor-specific cytotoxicity," Journal of Materials Chemistry $B$, vol. 1, no. 28, pp. 3494-3505, 2013.

[17] A. Petushkov, J. Intra, J. B. Graham, S. C. Larsen, and A. K. Salem, "Effect of crystal size and surface functionalization on the cytotoxicity of silicalite-1 nanoparticles," Chemical Research in Toxicology, vol. 22, no. 7, pp. 1359-1368, 2009.

[18] S. C. Larsen, "Nanocrystalline zeolites and zeolite structures: synthesis, characterization, and applications," Journal of Physical Chemistry C, vol. 111, no. 50, pp. 18464-18474, 2007.

[19] I. Braschi, S. Blasioli, L. Gigli, C. E. Gessa, A. Alberti, and A. Martucci, "Removal of sulfonamide antibiotics from water: evidence of adsorption into an organophilic zeolite Y by its structural modifications," Journal of Hazardous Materials, vol. 178, no. 1-3, pp. 218-225, 2010.

[20] N. Vilac, R. Amorim, O. Martinho et al., "Encapsulation of $\alpha$ cyano-4-hydroxycinnamic acid into a NaY zeolite," Journal of Materials Science, vol. 46, no. 23, pp. 7511-7516, 2011.

[21] M. Arruebo, R. Fernández-Pacheco, S. Irusta, J. Arbiol, M. R. Ibarra, and J. Santamaría, "Sustained release of doxorubicin from zeolite-magnetite nanocomposites prepared by mechanical activation," Nanotechnology, vol. 17, no. 16, article 4057, 2006.

[22] A. Datt, D. Fields, and S. C. Larsen, "An experimental and computational study of the loading and release of aspirin from zeolite HY," Journal of Physical Chemistry C, vol. 116, no. 40, pp. 21382-21390, 2012.

[23] A. Datt, E. A. Burns, N. A. Dhuna, and S. C. Larsen, "Loading and release of 5-fluorouracil from $\mathrm{HY}$ zeolites with varying $\mathrm{SiO}_{2} / \mathrm{Al}_{2} \mathrm{O}_{3}$ ratios," Microporous and Mesoporous Materials, vol. 167, pp. 182-187, 2013.

[24] M. Spanakis, N. Bouropoulos, D. Theodoropoulos et al., "Controlled release of 5-fluorouracil from microporous zeolites," Nanomedicine: Nanotechnology, Biology, and Medicine, vol. 10, no. 1, pp. 197-205, 2014.

[25] A. Oyane, H.-M. Kim, T. Furuya, T. Kokubo, T. Miyazaki, and T. Nakamura, "Preparation and assessment of revised simulated body fluids," Journal of Biomedical Materials Research-Part A, vol. 65, no. 2, pp. 188-195, 2003.

[26] S. Ahmed, M. Z. El-Faer, M. M. Abdillahi, M. A. B. Siddiqui, and S. A. I. Barri, "Investigation of the rapid crystallization method for the synthesis of MFI-type zeolites and study of the physicochemical properties of the products," Zeolites, vol. 17, no. 4, pp. 373-380, 1996.

[27] A. Saito and H. C. Foley, "High-resolution nitrogen and argon adsorption on ZSM-5 zeolites: effects of cation exchange and Si/Al ratio," Microporous Materials, vol. 3, no. 4-5, pp. 543-556, 1995.

[28] K. Sing, "Reporting physisorption data for gas/solid systems," Pure and Applied Chemistry, vol. 54, no. 11, pp. 2201-2218, 1982.

[29] J. Cejka, H. Van Bekkum, and C. Schueth, Introduction to Zeolite Molecular Sieves, Elsevier Science, New York, NY, USA, 3rd edition, 2007.

[30] H. Feng, C. Li, and H. Shan, "Effect of calcination temperature of kaolin microspheres on the in situ synthesis of ZSM-5," Catalysis Letters, vol. 129, no. 1-2, pp. 71-78, 2009.

[31] L. Shirazi, E. Jamshidi, and M. R. Ghasemi, "The effect of Si/Al ratio of ZSM-5 zeolite on its morphology, acidity and crystal size," Crystal Research and Technology, vol. 43, no. 12, pp. 13001306, 2008

[32] T. Heikkilä, J. Salonen, J. Tuura et al., "Evaluation of mesoporous TCPSi, MCM-41, SBA-15, and TUD-1 materials as API carriers for oral drug delivery," Drug Delivery, vol. 14, no. 6, pp. 337-347, 2007. 
[33] T. Higuchi, "Mechanism of sustained-action medication. Theoretical analysis of rate of release of solid drugs dispersed in solid matrices," Journal of Pharmaceutical Sciences, vol. 52, no. 12, pp. 1145-1149, 1963.

[34] E. Chevalier, M. Viana, A. Artaud, S. Haddouchi, and D. Chulia, "A novel application of the T-cell for flow-through dissolution: the case of bioceramics used as ibuprofen carrier," Talanta, vol. 77, no. 4, pp. 1545-1548, 2009. 

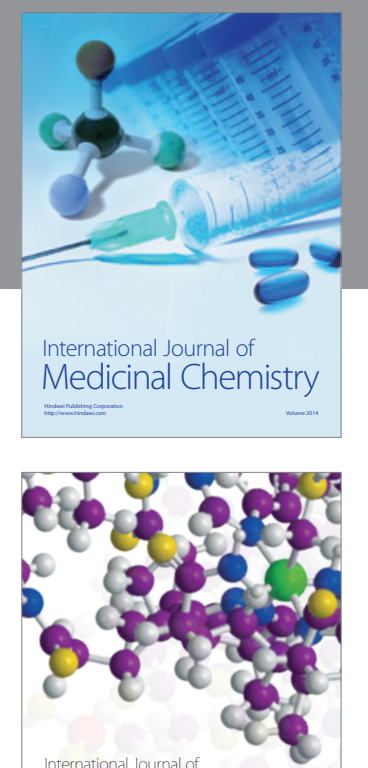

\section{Carbohydrate} Chemistry

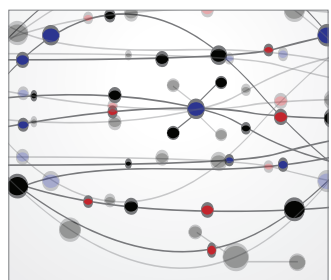

The Scientific World Journal
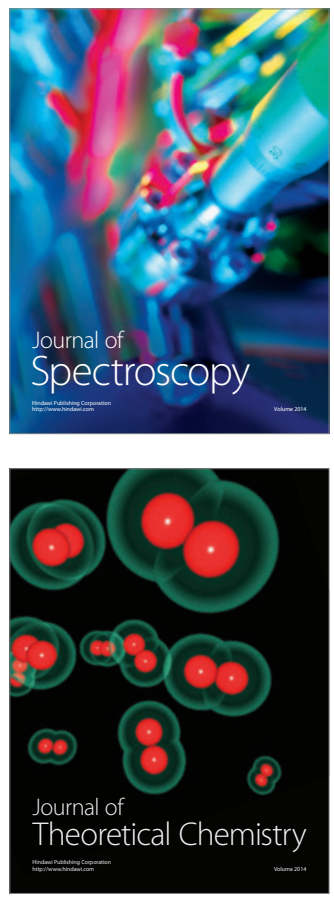
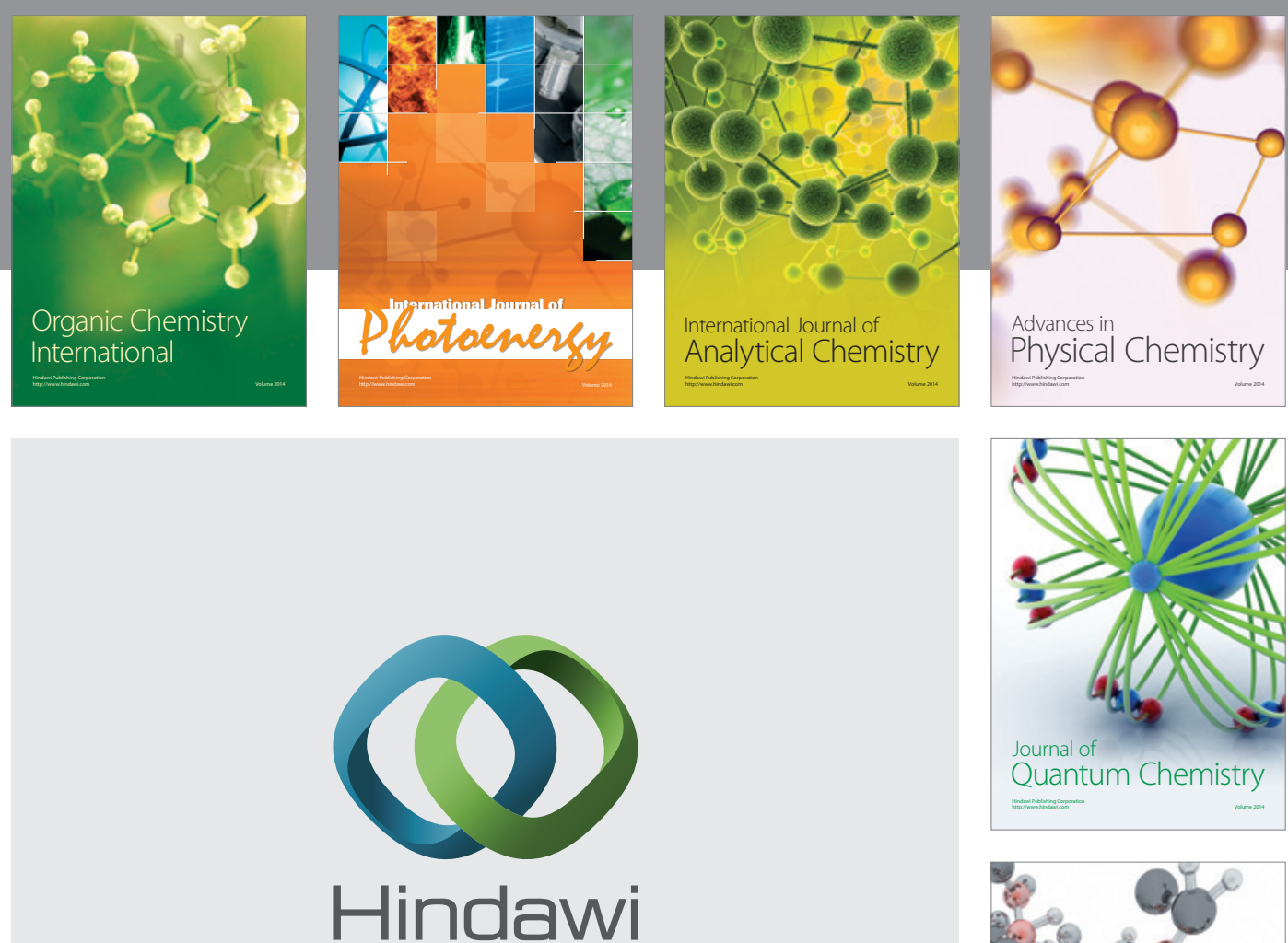

Submit your manuscripts at

http://www.hindawi.com

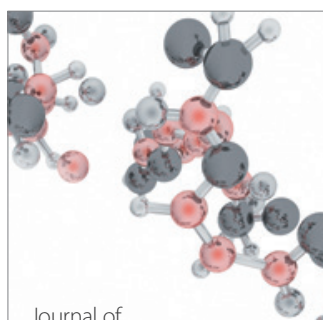

Analytical Methods

in Chemistry

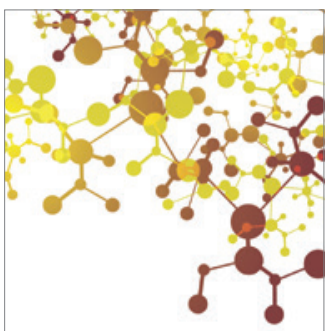

Journal of

Applied Chemistry

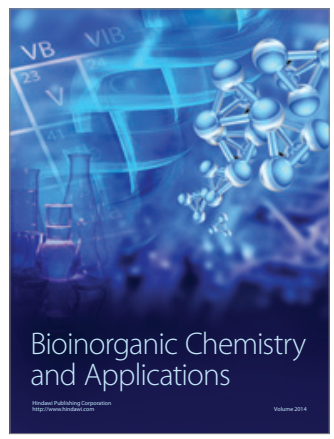

Inorganic Chemistry
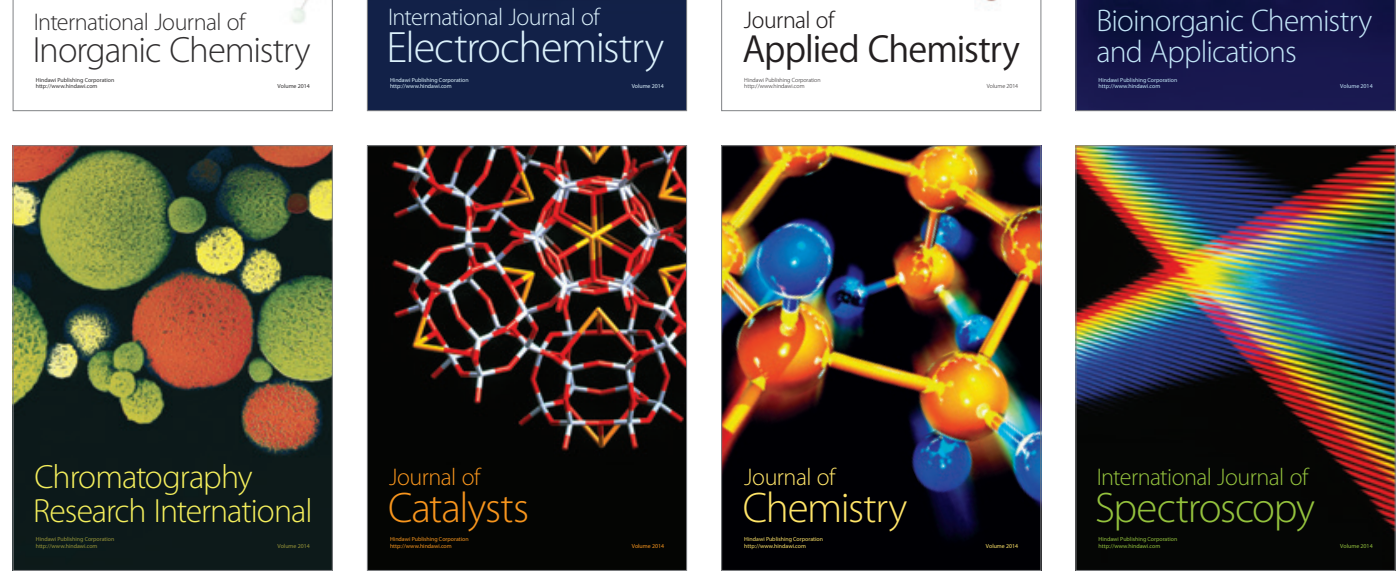